\title{
Willingness to Pay for Family Health Insurance: Evidence From Baglung and Kailali Districts of Nepal
}

\author{
Devaraj Acharya ${ }^{1}$, Bhimsen Devkota ${ }^{1} \&$ Ramesh Adhikari ${ }^{2}$ \\ ${ }^{1}$ Faculty of Education, Tribhuvan University, Kathmandu, Nepal \\ ${ }^{2}$ Geography and Population Department, Mahendra Ratna Campus, Tribhuvan University, Kathmandu, Nepal \\ Correspondence: Devaraj Acharya, Faculty of Education, Tribhuvan University, Kirtipur, Kathmandu, Nepal. Tel: \\ 977-985-701-2250. E-mail: drabmc@gmail.com
}

Received: September 23, 2018 Accepted: October 18, 2018 Online Published: November 28, 2018

doi:10.5539/gjhs.v10n12p144

URL: https://doi.org/10.5539/gjhs.v10n12p144

\begin{abstract}
Introduction: The Government of Nepal introduced a health insurance programme in three districts in 2016. However, it seems that there has not been systematic evidence on whether the current contribution amount (CCA) needed for enrolling in health insurance (HI), is acceptable for those who are willing to enroll. This article aims to assess the respondents' willingness to pay (WTP) for HI.
\end{abstract}

Methods: A cross-sectional study was conducted with 810 randomly selected households in Baglung and Kailali districts and the data was collected using a validated schedule. The socio-demographic characteristics were considered as independent and the WTP as dependent variables respectively. Univariate, bivariate and multivariate analysis were performed.

Results: Of the total respondents, 74 percent expressed that they could pay nearly three times as much as the CCA. Mean differences in WTP for HI were observed in terms of districts $(p<0.001)$, sex of the respondents $(\mathrm{p}<0.01)$, household headship $(p<0.05)$, mother tongue $(p<0.001)$, wealth status $(p<0.001)$, presence of chronic diseases in the family $(\mathrm{p}<0.05)$, enrollment in $\mathrm{HI}(\mathrm{p}<0.01)$, exposure to the radio/FM $(\mathrm{p}<0.05)$ and $\mathrm{TV}(\mathrm{p}<0.01)$, and access to health facilities $(p<0.01)$. The lieklyhood of WTP for HI were lower in Kailali than in Baglung $(\beta=-0.178$, $\mathrm{p}<0.001)$; with females than with males $(\beta=-0.076, \mathrm{p}<0.05)$; and with the age group $\leq 37$ years than $>37$ years $(\beta=$ $-0.090, \mathrm{p}<0.05)$.

Conclusion: The WTP for HI was nearly three times as high as the CCA for all health services if available to them. More than one fourth of the respondents did not know about HI. Therefore, appropriate interventions are needed for awareness raising which may support the WTP as well as enrollment in HI.

Keywords: Health insurance, Nepal, willingness to pay
Abbreviations
CCA: Current Contribution Amount
HH: Household
HI: Health Insurance
HIB: Health Insurance Board
WTP: Willingness to Pay

\section{Introduction}

The protection and promotion of health is essential for people not only for welfare but also for a sustainable socio-economic development (World Health Organization, 2010). Inequality caused by health financing in lower-middle income countries (LMIC) depends on out-of-pocket expenditure during receiving health services (Lofgren, Thanh, Chuc, Emmelin, \& Lindholm, 2008). An economic survey of Nepal shows that at the end of the fiscal year 2015/16, 21.6 percent of the total population accounting for more than six million live below the poverty line (Ministry of Finance, n.d.) and struggle for subsistence. Most of the LMICs have budget less than two percent of the total gross domestic products. So, the government should not depend only on premium collection or the contribution amount from the people (Nosratnejad, Rashidian, \& Dror, 2016). According to 
Maslow, people fulfill their basic needs first. When their basic needs are fulfilled, they strive for other needs (Stoyanov, 2017). In this context, people do not search for additional needs until their basic needs, such as food, shelter, and clothes are fulfilled. This means that people can hardly think about additional necessities if they do not meet their basic needs.

$\mathrm{HI}$ is a new phenomenon for Nepalese people. Nepalese people only recently have had some experience in health insurance (HI). The Government of Nepal (GoN) initiated HI as a Social Health Security programme in three districts, namely, Kailali, Baglung and Ilam in 2016 and further expanded recently to 30 more districts (Health Insurance Board, n.d.). The United Mission to Nepal initiated the HI programme at Ashrang in 1976, which was known as Lalitpur Medical Insurance. Later, in 2000, B.P. Koirala Institute of Health Sciences had also offered hospital-based micro-social health insurance schemes for rural and urban households. However, those schemes could not be continued (KOICA - Nepal Health Insurance Support Project [NHISP], 2014).

The GoN initiated a free health care policy for the ultra-poor, senior citizens, people wih disabilities and female community health volunteers at Primary Health Centres (PHC) and district hospitals since December, 2006. As per the provision of the Interim Constitution of Nepal 2007, the GoN initiated a free-of-cost basic health service from sub-health posts (SHPs) and health posts (HPs) since $15^{\text {th }}$ January, 2008. Similarly, essential health services were provided free of cost at PHCs since November, 2008. Some 40 types of essential drugs and emergency services were made available at free of cost in the hospitals having fewer than 25 beds since January, 2009 (Prasai, 2013). Apart from these, the GoN has also offered the reverse paying system (an incentive as travel cost for those who utilize the services) for natal care, uterine prolapse treatment, and some other services for special target groups. There are also provisions of subsidies for some heavily cost-needing cases, such as heart related diseases, cancer, kidney related diseases, spinal and head injuries, Alzheimer's disease, sickle cell anaemia as well as Parkinson's disease. Moreover, senior citizens above 75 years and children below 15 years can receive some subsidies including 70 kinds of medicines at free of cost as per the guidelines (Health Insurance Board, n.d.). More recently, the Constitution of Nepal 2015 has provision that basic health service as a fundamental right of the citizens (Nepal Law Commission, n.d.). As a result, the GoN has offered basic health services that includes some 70 types of drugs and medicines from the government health facilities free of cost (Health Insurance Board, n.d.).

A study in Nepal found that only one third (33.6\%) of the households have an access to public hospitals or primary health centers within 30 minutes, while 61.8 percent households to SHP/HP and more than half (53.4\%) households to private clinics/hospitals had an access within 30 minutes (Central Bureau of Statistics, 2011). A recent study conducted in Kailali shows that 76 percent of households have an access to health facilities within half an hour. The study further shows that just over a quarter (28\%) of households were satisfied with the services they received from the government health facilities whereas 56 percent of them were satisfied with the health services received from the private sector (KOICA-NHISP, 2014).

One study shows that, only four percent of the total households have participated in the HI scheme and only 11 percent households had knowledge about HI (Health Research and Social Development Forum [HERD], 2016). It seems to be a big challenge for the implementation of the health insurance programme (HIP) since only 5.2 and 3.5 percent HHs have utilized health services from PHCs and government hospitals respectively even though they are provided free of cost. Similarly, the utilization of regular health services also appears weak. The rates of tetanus vaccination, $4^{\text {th }}$ ante-natal checkup and institutional delivery are 40,59 and 50 percents respectively (Department of Health Services, 2018). The Health Insurance Board (HIB) is still unanswered whether the people can pay for the contribution amount of Nepalese Rupees (NRs.) 2500/- per year for up to 5-member family that covers up to NRs. 50,000/- per year (Health Insurance Board, n.d.). This article aims to assess the respondents' willingness to pay (WTP) for health insurance (HI) in two pilot districts of Nepal.

\section{Methods}

A cross-sectional survey design was used in Kailali and Baglung from March to May in 2018. An interview schedule (IS) was used for data collection. The interview schedule was administrated face to face with the respondents during home visits. The sample size was calculated by using the formula below (Kothari, 2006) assuming fifty-fifty probability with a non-response rate of five percent.

$$
n=\left(z^{2} \times p \times q\right) / e^{2}
$$

By adjusting the non-response rate, the sample size of 405 was taken from the enrolled families and the same number of sample was taken from the non-enrolled family. Thus, the total sample 810, the sample was distributed proportionately; $566(283+283)$ from Kailali and $244(122+122)$ from Baglung as per Census data 
2011 (Central Bureau of Statistics, 2014). This study included the households (HHs) enrolled in HIB, formerly known as Social Health Security Development Committee (SHSDC), before January $15^{\text {th }} 2018$ as enrolled families whereas those insured from other than the HIB were excluded. The list of the enrolled households was obtained from HIB District Office Kailali and Baglung. The sample was selected randomly from the list of enrolled families and the nearest non-enrolled families was selected as non-enrolled households. In the case of the rejection to participate, the nearest households was selected. For the response, the household head or senior member of the family was interviewed and in the case of the absence or rejection to by him/her, another senior member available at the time of home visit was interviewed.

An ethical approval of the study was obtained from Nepal Health Research Council. Informed consent was taken from each respondent before the interview. The data were entered into the Statistical Package for Social Science [SPSS] version 20 and were cross-checked for reducing inconsistency or errors during the entry. For the analysis of the data, three kinds of analysis were conducted: univariate, bivariate; and multivariate. The independent continuous variables were converted into categorical and dichotomous characters for the t-test and the multivariate analysis.

\section{Results}

In this section, the results of the study are organized under four headings, namely, socio-demographic characteristics of households and respondents; WTP for HI; characteristics of households and respondents and WTP for HI; and coefficient of socio-demographic variables on WTP for HI.

\subsection{Socio-Demographic Characteristics of the Households and the Respondents}

A total of 810 household heads were interviewed. In the case of their absence or rejection to participate, another senior member of the household was interviewed. In the sample, Kailali consisted of approximately 70 percent and Baglung covered 30 percent of the total respondents. Of them 74 percent were from urban areas (municipalities) and about 26 percent were from rural areas (rural municipalities). Of these respondents, 51 percent were female. Similarly, 65 percent of them were household heads. About 60 percent respondents ranged in age from 20 to 40 years. The mean and SD and median and mode of the ages of the respondents were $39 \pm 13$, 37, 35 years respectively. Of the respondents, about 44, 36, 10 and five percent were from the Aadibasis/Janajatis, Brahmans/Chhetris, Dalits and Others/Dasnamis/Thakuris respectively. More than 91 percent of the respondents were Hindus. As regards language, more than 58 percent of the respondents stated that their mother tongue was Nepali whereas 30 and eight percent of the respondents were Tharu and Doteli respectively. Agriculture, followed by service and business, was the main source of their income. Out of the total respondents about 93 percent were literate, with 29, 26 and 12 percent of them having completed basic education, school level education and higher education respectively. Fifty-nine percent of the respondents were from joint families. The average, median and mode of the family size were 5.6 \pm 1.9 , five and five respectively, in which about 56, 42 and two percent households had up to five members, six to 10 members and more than 10 members respectively. According to the data, the households' highest expenditure was in education followed by clothes/utensils, health care, food and communication. More than half $(51.2 \%)$ of the households were economically able for feeding their families. About 35 percent households had some kinds of chronic diseases in family members. Of them, more than one third (33.9\%) had heart related problems followed by gastritis (25.7\%), joints or bone related problems (22.1\%), respiratory diseases (20.4\%) and diabetes (17.9\%).

The average duration of the HI enrollment was $14 \pm 6$ months, and it was more than a year since more than half $(51.6 \%)$ of the them had enrolled in HI. About half $(47.7 \%)$ of the respondents were informed about HI from the radio/FM whereas only 38.3 percent of the respondents had received HI related information from television. More than three fourth (76 and $75.4 \%$ ) of the respondents had the radio/FM and television respectively at their homes and 14.2 percent of them had the internet access. Nearly half $(48 \%)$ of the respondents expressed that they were susceptible to health problems. The mean and median for time to reach health facilities for them were $30 \pm 22$ and 30 minutes respectively whereas 72.2 percent of the respondents reported that they could visit health facilities within half an hour. More than 30 percent of the respondents expressed that a minimum of one of their family members was aboard at the time of the interview. The demographic characteristics of the respondents and households are presented in Table 1 . 
Table 1. Socio-demographic character of respondents and households

\begin{tabular}{|c|c|c|c|}
\hline Measures & Attributes & Number & Percent \\
\hline \multirow[t]{2}{*}{ District } & Baglung & 244 & 30.1 \\
\hline & Kailali & 566 & 69.9 \\
\hline \multirow[t]{2}{*}{ Address } & Urban & 600 & 74.1 \\
\hline & Rural & 210 & 25.9 \\
\hline \multirow[t]{2}{*}{ Sex of respondents } & Male & 397 & 49.0 \\
\hline & Female & 413 & 51.0 \\
\hline \multirow[t]{2}{*}{ Household head } & No & 276 & 34.1 \\
\hline & Yes & 534 & 65.9 \\
\hline \multirow[t]{4}{*}{ Age group } & Up to 20 years & 23 & 2.8 \\
\hline & 21 to 40 years & 482 & 59.5 \\
\hline & 41 to 60 years & 233 & 28.8 \\
\hline & More than 60 years & 72 & 8.9 \\
\hline \multirow[t]{6}{*}{ Caste/Ethnicity } & Dalit & 88 & 10.9 \\
\hline & Aadibasi/Janajatis & 352 & 43.5 \\
\hline & Madhesi & 14 & 1.7 \\
\hline & Muslim & 19 & 2.3 \\
\hline & Brahman/Chhetri & 293 & 36.2 \\
\hline & Others/Dasnami/Thakuri & 44 & 5.4 \\
\hline \multirow[t]{5}{*}{ Religion } & Hindu & 739 & 91.2 \\
\hline & Buddhist & 26 & 3.2 \\
\hline & Islam & 19 & 2.3 \\
\hline & Christian & 25 & 3.1 \\
\hline & Others & 1 & .1 \\
\hline \multirow[t]{5}{*}{ Mother tongue } & Nepali & 472 & 58.3 \\
\hline & Tharu & 241 & 29.8 \\
\hline & Doteli & 66 & 8.1 \\
\hline & Aachhami & 3 & .4 \\
\hline & Others & 28 & 3.5 \\
\hline \multirow[t]{2}{*}{ Literacy status } & Illiterate & 60 & 7.4 \\
\hline & Literate & 750 & 92.6 \\
\hline Educational level & Literate only & 246 & 32.8 \\
\hline \multirow[t]{3}{*}{$(\mathrm{n}=750)$} & Basic Education & 214 & 28.5 \\
\hline & School Level education & 197 & 26.3 \\
\hline & Bachelor or Above & 93 & 12.4 \\
\hline \multirow[t]{2}{*}{ Type of family } & Nuclear & 332 & 41.0 \\
\hline & Joint & 478 & 59.0 \\
\hline \multirow[t]{3}{*}{ Size of family } & Up to 5 members & 457 & 56.4 \\
\hline & 6 to 10 members & 340 & 42.0 \\
\hline & More than 10 members & 13 & 1.6 \\
\hline
\end{tabular}




\begin{tabular}{|c|c|c|c|}
\hline \multirow[t]{5}{*}{ Wealth status } & Poorest & 162 & 20.0 \\
\hline & Poor & 162 & 20.0 \\
\hline & Middle & 162 & 20.0 \\
\hline & Rich & 162 & 20.0 \\
\hline & Richest & 162 & 20.0 \\
\hline \multirow[t]{5}{*}{ Income/production covers feeding } & Throughout the year & 415 & 51.2 \\
\hline & 9 to 12 months & 61 & 7.5 \\
\hline & 6 to 9 months & 90 & 11.1 \\
\hline & 3 to 6 months & 114 & 14.1 \\
\hline & Less than 3 months & 130 & 16.0 \\
\hline \multirow{2}{*}{$\begin{array}{l}\text { Family member having chronic } \\
\text { diseases }\end{array}$} & No & 530 & 65.4 \\
\hline & Yes & 280 & 34.6 \\
\hline \multirow[t]{2}{*}{ Enrolled in health insurance } & No & 405 & 50.0 \\
\hline & Yes & 405 & 50.0 \\
\hline \multirow[t]{2}{*}{ Knowledge about health insurance } & No & 227 & 28.0 \\
\hline & Yes & 583 & 72.0 \\
\hline \multirow{3}{*}{$\begin{array}{l}\text { Willingness to pay for health } \\
\text { insurance }\end{array}$} & Up to Rs $500 /-$ & 211 & 26.0 \\
\hline & Rs 501 to 1500 & 395 & 48.8 \\
\hline & More than Rs.1500/- & 204 & 25.2 \\
\hline \multirow{2}{*}{$\begin{array}{l}\text { Listened HI related information from } \\
\text { Radio/FM }\end{array}$} & No & 424 & 52.3 \\
\hline & Yes & 386 & 47.7 \\
\hline \multirow{2}{*}{$\begin{array}{l}\text { Watched HI related information in } \\
\text { TV }\end{array}$} & No & 500 & 61.7 \\
\hline & Yes & 310 & 38.3 \\
\hline \multirow[t]{2}{*}{ Susceptible to health problem } & No & 424 & 52.3 \\
\hline & Yes & 386 & 47.7 \\
\hline \multirow[t]{3}{*}{ Time to reach health facilities } & Up to 30 minutes & 585 & 72.2 \\
\hline & 31 to 60 minutes & 190 & 23.5 \\
\hline & More than 60 minutes & 35 & 4.3 \\
\hline \multirow[t]{2}{*}{ Family member aboard } & No & 566 & 69.9 \\
\hline & Yes & 244 & 30.1 \\
\hline Total & & 810 & 100.0 \\
\hline
\end{tabular}

\subsection{Willingness to Pay for Health Insurance}

It can be assumed that the respondents' WTP depends upon their socio-demographic characteristics and satisfaction from the services made available to them (Thi Thuy Nga, FitzGerald, \& Dunne, 2018). In this study, the respondents were asked how much they wanted to pay a year per person if the HIP covers all the health services available in the country. In response, more than one fourth (26\%) of the respondents reported that they could pay up to 500/- Nepalese Rupees (NRs.) for HI which was less or equivalent to the current contribution amount (CCA) for enrollment. Yet, nearly half of the respondents (49\%) expressed that they could pay up to NRs. 1500 for HI which was more than the CCA but less or equivalent to the average amount of the respondents' willingness. One fourth $(25.2 \%)$ of them replied that they could pay more than NRs. 1500 , which was nearly three times as much as the CCA. 
Table 2. Willingness to pay for health insurance

\begin{tabular}{|c|c|c|c|c|c|c|c|c|c|}
\hline Amount (Nepalese Rupees) * & No. & Percent & Mean & Median & Mode & SD & Range & \multicolumn{2}{|c|}{ MinimumMaximum } \\
\hline Up to Rs. 500/- & 211 & 26.0 & & & & & & & \\
\hline Rs. 501 to 1500 & 395 & 48.8 & 1429 & 1000 & 1000 & 1736 & 24800 & 200 & 25000 \\
\hline More than Rs.1500/- & 204 & 25.2 & & & & & & & \\
\hline
\end{tabular}

Note. * per person per year.

As per the current provision of HIB, a family up to 5 members has to pay NRs. 2500 per year that covers up to NRs. 50,000 of the health care cost. For an additional member of a family they should pay an extra NRs. 425 covering an additional NRs. 10,000 per person and the programme covers a maximum NRs. 100,000 per year (Health Insurance Board, n.d.). District Assessment for HI in Kailali District shows that a total of NRs. 6,023.5 was paid on the average as a treatment cost during the latest health facility visit seeking health care while the highest expenditure (27.8\%) was in pharmacy (KOICA-NHISP, 2014). The data show that 74 percent of the households wanted to pay more than the CCA offered by HIB, and the respondents wanted to pay nearly three times more on the average than the CCA if all health services were available to them (Table 2).

\subsection{Characteristics of the Respondents/Households and Willingness to Pay for Health Insurance}

It is found that different socio-demographic characteristics bring differences in the WTP for HI. More than four fifth $(84.4 \%)$ of the respondents from Baglung wanted to pay more than the CCA compared to Kailali (69\%) and the respondents from Baglung had higher WTP compared to Kailali, that is NRs.1977.6 and 1191.8 respectively $(p<0.001)$. Similarly, the households from rural areas had more WTP than those from the urban areas, which accounts for 79.5 and 72 percent respectively. In the same way, the male respondents who were household heads had higher WTP compared to the female. WTP for HI was higher in the male respondents (NRs. 1610) than that of the female (NRs. 1255) $(\mathrm{p}<0.01)$. Interestingly, the higher the age the higher WTP for HI had been found. Respondents aged more than 60 years had higher WTP for HI. Similarly, households from the Other castes had more WTP for HI compared to Aadibasis/Janajatis whereas households belonging to Brahmans/Chhetris had more WTP than the other castes. In the case of religion, non-Hindu households had a higher chance to pay for HI. The data shows that the Nepali native speakers had chances to pay a greater amounts (NRs.1617) compared to other language speakers (NRs.1166) $(\mathrm{p}<0.001)$. Literate families had higher chances to pay high amounts than the illiterate ones. The respondents having a higher educational status seemed to have higher amounts (NRs. 1798) of WTP for HI compared to those with a lower educational status $(\mathrm{p}<0.05)$. Similarly, WTP seemed higher in nuclear families than joint families. The rich households wanted to pay more (NRs 1638 vs. NRs. 1221) in comparison to poor families $(p<0.001)$. The households that economically sustained for feeding had more willingness for HI than households that were unable to feed themselves throughout the year. The households having chronic diseases had higher chances to pay higher amounts for $\mathrm{HI}(\mathrm{p}<0.05)$.

Table 3. Characteristics of respondents/households and willingness to pay for health insurance

\begin{tabular}{lllll}
\hline Variables & Attributes & No. & Mean & SD \\
\hline District*** & Baglung & 244 & 1977.64 & 1992.87 \\
& Kailali & 566 & 1191.83 & 1555.98 \\
\hline Place of residence & Urban & 600 & 1396.80 & 1776.97 \\
& Rural & 210 & 1519.25 & 1614.13 \\
\hline \multirow{2}{*}{ Sex** } & Male & 397 & 1609.59 & 1872.41 \\
& Female & 413 & 1254.51 & 1576.84 \\
\hline \multirow{2}{*}{ Age } & $\leq 37$ years & 414 & 1396.39 & 1898.23 \\
& $>37$ years & 396 & 1462.16 & 1550.21 \\
\hline Household head* & No & 276 & 1251.06 & 1318.62 \\
& Yes & 534 & 1520.28 & 1911.22 \\
\hline
\end{tabular}




\begin{tabular}{|c|c|c|c|c|}
\hline \multirow{2}{*}{ Caste } & Others & 458 & 1447.75 & 1646.31 \\
\hline & Aadibasi/Janajatis & 352 & 1403.55 & 1848.44 \\
\hline \multirow{2}{*}{ Religion } & Others & 71 & 1467.27 & 1396.59 \\
\hline & Hindu & 739 & 1424.82 & 1765.99 \\
\hline \multirow{2}{*}{ Mother tongue ${ }^{* * *}$} & Others & 338 & 1165.69 & 1408.16 \\
\hline & Nepali & 472 & 1616.78 & 1916.49 \\
\hline \multirow{2}{*}{ Literary } & Illiterate & 60 & 1273.13 & 982.99 \\
\hline & Literate & 750 & 1440.98 & 1782.46 \\
\hline \multirow{2}{*}{ Type of family } & Nuclear & 332 & 1507.67 & 2066.55 \\
\hline & Joint & 478 & 1373.59 & 1463.16 \\
\hline \multirow{2}{*}{ Size of family } & $>5$ members & 353 & 1374.47 & 1464.82 \\
\hline & $\leq 5$ members & 457 & 1470.32 & 1920.09 \\
\hline \multirow{2}{*}{ Wealth status $* * *$} & Poor & 407 & 1221.25 & 1267.82 \\
\hline & Rich & 403 & 1637.90 & 2086.76 \\
\hline \multirow{2}{*}{ Cover to feed by income } & $<$ a year & 395 & 1485.65 & 1629.15 \\
\hline & $\geq$ a year & 415 & 1374.19 & 1832.36 \\
\hline \multirow{2}{*}{ Chronic diseases in family* } & No & 530 & 1325.98 & 1584.90 \\
\hline & Yes & 280 & 1622.69 & 1979.60 \\
\hline \multirow{2}{*}{ Enrolled in $\mathrm{HI}^{* * *}$} & No & 405 & 1230.08 & 1458.02 \\
\hline & Yes & 405 & 1627.01 & 1957.18 \\
\hline \multirow{2}{*}{ Knowledge on $\mathrm{HI}^{* *}$} & No & 227 & 1141.14 & 1550.12 \\
\hline & Yes & 583 & 1540.45 & 1792.10 \\
\hline \multirow{2}{*}{ Listened HI information from Radio/FM** } & No & 424 & 1299.76 & 1770.50 \\
\hline & Yes & 386 & 1570.00 & 1688.43 \\
\hline \multirow{2}{*}{ Watched $\mathrm{HI}$ related information in $\mathrm{TV}^{* *}$} & No & 500 & 1287.65 & 1860.71 \\
\hline & Yes & 310 & 1655.79 & 1488.56 \\
\hline \multirow{2}{*}{ Susceptible to health problem } & No & 424 & 1405.93 & 1544.63 \\
\hline & Yes & 386 & 1453.39 & 1926.30 \\
\hline \multirow{2}{*}{ Access to health facility** } & $>30$ minutes & 225 & 1217.13 & 1098.81 \\
\hline & $\leq 30$ minutes & 585 & 1509.86 & 1920.46 \\
\hline \multirow{2}{*}{ Family member aboard } & No & 566 & 1361.45 & 1852.27 \\
\hline & Yes & 244 & 1584.18 & 1422.00 \\
\hline Total & & 810 & 1429 & 1736 \\
\hline
\end{tabular}

Note. Significant at $* \mathrm{p}<0.05, * * \mathrm{p}<0.01, * * * \mathrm{p}<0.001$

Similarly, households having more than 12 to 18 months' experience of the enrollment had higher chances of WTP than those having experience less than one year and more than 18 months of the enrollment $(\mathrm{p}<0.01)$. People who were enrolled in HIP had higher chances to pay than the non-enrolled $(p<0.001)$. Households that renewed the enrollment of HI reported a greater amount of WTP for HI $(p<0.05)$. The respondents having knowledge about HI seemed to have more WTP compared to those who were unknown about HI $(p<0.01)$. Those who listened to the Radio/FM had more WTP (NRs 1570 vs NRs 1300) than the non-listeners $(p<0.05)$. The respondents who watched television and knew about HI information had higher WTP (1656 vs 1288) than those who did not $(\mathrm{p}<0.01)$. Families who considered susceptible (self-reported) to diseases had higher WTP than the 
non-susceptible. The households having an access to health facilities within 30 minutes had more WTP (1510 vs 1217) than those having an access to health facilities accessible in more than 30 minutes $(\mathrm{p}<0.01)$. The data also shows households having family members aboard had more WTP (1584) than those who did not (1361). Moreover, the data show that different characteristics of households as well as personal attributes influenced the WTP for HI. In short, the WTP for HI depends on different socio-demographic characteristics and education of the respondents and households (Table 3).

\subsection{Coefficient of Socio-Demographic Variables on Willingness to Pay for Health Insurance}

Socio-demographic factors are strong predictors for WTP for HI (Thi Thuy Nga et al., 2018). The multivariate analysis found that geography (district), sex of the respondents, age group of the respondents, household headship, caste/ethnicity, enrollment in HI and an access to health facilities were significant predictors for WTP for HI. The households form Kailali had lower chances (negative) of WTP for HI than those from Baglung ( $\beta=-$ $0.178, \mathrm{p}<0.001)$. Rural households tended to have higher chances to pay for HI but not statistically significant $((\beta=0.067)$ whereas female respondents had significantly low WTP for HI $(\beta=-0.076, p<0.05)$. The data showed significant but negative effects on age group of less than 37 years compared to equal or more than 37 years $(\beta=-0.090, p<0.05)$. Household headship was another significant forecaster for WTP. A chance of a positive effect on WTP for HI $(\beta=0.078, \mathrm{p}<0.05)$ was observed if the respondent him/herself was the household head. The Aadibasis/Janajatis appeared more positive on WTP for HI $(\beta=0.108, \mathrm{p}<0.05)$ in comparison to other castes. The households enrolled in HI appeared to be a positive and significant predictor for WTP. The data show that the enrolled households had more WTP than the non-enrolled households $(\beta=0.110, \mathrm{p}<0.01)$.

Table 4. Coefficient of socio-demographic variables on willingness to pay for health insurance

\begin{tabular}{|c|c|c|c|}
\hline & & $\beta$ & $\mathrm{t}$ \\
\hline \multirow{2}{*}{ District } & Baglung (ref.) & & \\
\hline & Kailali*** & -.178 & -4.116 \\
\hline \multirow{2}{*}{ Place of residence } & Urban (ref.) & & \\
\hline & Rural & .067 & 1.840 \\
\hline \multirow{2}{*}{ Sex } & Male (ref.) & & \\
\hline & Female* & -.076 & -2.007 \\
\hline \multirow{2}{*}{ Age } & $\leq 37$ years (ref.) & & \\
\hline & $>37$ years $*$ & -.090 & -2.240 \\
\hline \multirow{2}{*}{ Household head } & No (ref.) & & \\
\hline & Yes* & .078 & 1.961 \\
\hline \multirow{2}{*}{ Caste } & Others (ref.) & & \\
\hline & Aadibasi/Janajatis* & .108 & 2.116 \\
\hline \multirow{2}{*}{ Religion } & Others (ref.) & & \\
\hline & Hindu & -.039 & -1.094 \\
\hline \multirow{2}{*}{ Mother tongue } & Others (ref.) & & \\
\hline & Nepali & .026 & .513 \\
\hline \multirow{2}{*}{ Literary } & Illiterate (ref.) & & \\
\hline & Literate & -.002 & -.042 \\
\hline \multirow{2}{*}{ Type of family } & Nuclear (ref.) & & \\
\hline & Joint & -.060 & -1.395 \\
\hline \multirow{2}{*}{ Size of family } & $>5$ members (ref.) & & \\
\hline & $\leq 5$ members & -.006 & -.131 \\
\hline
\end{tabular}




\begin{tabular}{|c|c|c|c|}
\hline \multirow{2}{*}{ Wealth status } & \multicolumn{3}{|l|}{ Poor (ref.) } \\
\hline & Rich & .070 & 1.817 \\
\hline \multirow{2}{*}{ Cover to feed by income } & $<$ a year (ref.) & & \\
\hline & $\geq a$ year & -.001 & -.019 \\
\hline \multirow{2}{*}{ Chronic diseases in family } & No (ref.) & & \\
\hline & Yes & .068 & 1.851 \\
\hline \multirow{2}{*}{ Enrolled in $\mathrm{HI}$} & No (ref.) & & \\
\hline & Yes* & .110 & 2.591 \\
\hline \multirow{2}{*}{ Knowledge on HI } & No (ref.) & & \\
\hline & Yes & -.007 & -.160 \\
\hline \multirow{2}{*}{ Listened HI information from Radio/FM } & No (ref.) & & \\
\hline & Yes & .028 & .723 \\
\hline \multirow{2}{*}{ Watched $\mathrm{HI}$ related information in $\mathrm{TV}$} & No (ref.) & & \\
\hline & Yes & .016 & .397 \\
\hline \multirow{2}{*}{ Susceptible to health problem } & No (ref.) & & \\
\hline & Yes & -.039 & -1.063 \\
\hline \multirow{2}{*}{ Access to health facility } & $>30$ minutes (ref.) & & \\
\hline & $\leq 30$ minutes* & .091 & 2.516 \\
\hline \multirow{2}{*}{ Family member aboard } & No (ref.) & & \\
\hline & Yes & .039 & 1.069 \\
\hline Constant & & $2.776^{* *}$ & 2.776 \\
\hline Adjusted R Square & & 0.073 & \\
\hline
\end{tabular}

Note. Significant at $* \mathrm{p}<0.05, * * \mathrm{p}<0.01,{ }^{* * *} \mathrm{p}<0.001$.

Similarly, the households having an access to health facilities within half an hour were likely to pay more WTP than those having that more than half an hour $(\beta=0.091, \mathrm{p}<0.05)$. Variables such as religion, mother tongue, listening to/watching HI related information form Radio/FM and television, susceptibility to health problems, and having family members aboard stand out as the positive predictors for WTP, not statistically significant. Interestingly literacy, family type, family size, income covering to food, knowledge on $\mathrm{HI}$; and susceptibility to health problems were likely to yield lower WTP for HI. Table 4 reveals the result of the coefficient of socio-demographic characteristics of the respondents and households and WTP for HI.

\section{Discussion}

Nepal's health care system needs reforms in efficiency of health facilities, motivation of health workers, and availability of drugs. Likewise, timely and prompt care of patients lead to quality of service and ultimately that leads to family enrollment in HI (Mishra, Khanal, Karki, Kallestrup, \& Enemark, 2015). WTP for HI mainly depends upon three factors: households' ability to pay, access to health facilities and quality of health services available to them (Ramadhan, Rahmadi, \& Djuhaeni, 2015). Health services require a sufficient budget for its quality maintenance. Many countries have allocated limited budgets for health (Shimamura, Matsushima, Yamada, \& Nguyen, 2018). LMICs cannot allocate a sufficient budget for the health sector and fail to meet the demands of people for health services. Some studies suggest that government's efforts alone may not be sufficient to overcome health problems. So, the informal sectors should be operated for HI (Bärnighausen, Liu, Zhang, \& Sauerborn, 2007). In Nepal, the current provision for the enrollment in HI is about NRs. 500 per person ( 2500 for up to a 5 -member family) per year. It is found that the respondents have nearly three times higher affordability than the CCA on the average. The greater coverage of health services leads to more willingness to pay (Lang \& Lai, 2008).

The data in this study suggests that WTP for HI is influenced by the respondents' place of residence in terms of 
geography (districts), sex, household headship, native language, wealth status, presence of chronic diseases in the family, enrollment in HIP, knowledge regarding HI, exposure to the media: the Radio/FM or TV and an easy access to health facilities (within half an hour). Another study from Malaysia shows a similar result that the WTP for HI was influenced by caste, level of education, household's wealth status and presence of chronic diseases in the family (Shafie \& Hassali, 2013). Similarly, a study in Nigeria reveals that the WTP was influenced by the stakeholders' age, sex, education, family size, income and past experience related to health expenditure (Babatunde et al., 2012). On the other hand, there were mean differences but not significant for WTP for HI among the participants in terms of residence, living in rural or urban areas, age, religion, type of family, family size, feeling of being susceptible to the health problems and family members working aboard. However, a study in Bangladesh shows that households from urban area had more WTP in comparison to the rural area (Ahmed et al., 2016).

In this study, more than a quarter (28\%) respondents expressed that they were unaware about HI. Similarly, more than half $(52 \%)$ of the respondents informed that they were not susceptible to health problems. A study in Taiwan claims that women and senior citizen were less likely to pay for health protection (Lang \& Lai, 2008). A study in Punjab (India) shows that the low level of awareness seems barriers to the subscription of HI policy, and age, sex, occupation and income played significant differences in the subscription of HI and WTP as well (Bawa \& Ruchita, 2011). However, a study in Indonesia shows that more than half (57.6\%) of the participants were able to pay the required amount whereas only 17.4 percent of the respondents showed their willingness to pay for the required amount. So, it does not mean that more or less of WTP only depend on the ability of the stakeholders to pay for HI (Ramadhan et al., 2015). A systematic review of WTP for HI in LMICs shows that there was a neutral effect of marital status and families having children under five years on WTP, whereas the male and a large family size had a positive relationship with WTP but older age people were less likely to pay more for HI. Similarly, the income level and the level of education, employment status and the rural residence had a positive relationship with WTP. The distance to health facilities had a negative relationship. The past hospitalization experiences and the experiences of enrolling in HI were likely to yield higher WTP for HI (Nosratnejad et al., 2016). Nguyen and Hoang (2017) found that the knowledge on HI and chronic diseases in the family had a positive relationship to pay. The study suggested conducting awareness on HI that contributes to high WTP for HI. Similar suggestions were proposed by Ghosh (2013), Lofgren et al. (2008) and Bawa and Ruchita (2011).

\section{Conclusion}

$\mathrm{HI}$ is a recently lunched government service for the Nepalese people. The findings indicate that the number of people who know about $\mathrm{HI}$ is increasing although nearly one-third of the household heads or senior members of the families still do not know about it. It indicates that appropriate interventions are necessary for raising awareness about HI. The study shows that WTP for HI is determined by socio-demographic variables. There were nearly similar results in both bivariate and multivariate analyses. Some variables, such as district, sex, household headship, enrollment in HI; and access to health facility were the key influencing factors for WTP, which were statistically significant in both bivariate and multivariate analyses, whereas native language, wealth status, households having chronic diseases, access to the Radio/FM and television had significant influence on WTP resulted from the bivariate analysis. Some other variables made differences in willingness to pay for financial protection for health, but were not statistically significant. Therefore, appropriate interventions are needed for raising individuals' and households' awareness about $\mathrm{HI}$ as well as quality of health services that may increase the WTP for health insurance.

\section{Authors' Contribution}

DA conducted data collection, editing, entry and cleaning and prepared the draft of this paper. BD supervised syudy design, data collection and review the draft. RA analyzed the data. All of them agreed to submit the article for publication.

\section{Acknowledgements}

The authors thank University Grants Commission, Nepal for providing financial support for this study and Mr. Kamal Kumar Poudel for copy editing. They are also equally indepted to the anonymous reviewers.

\section{Competing Interests Statement}

The authors declare that they have no conflict of interest with this work.

\section{References}

Ahmed, S., Hoque, M. E., Sarker, A. R., Sultana, M., Islam, Z., Gazi, R., \& Khan, J. A. M. (2016). 
Willingness-to-pay for community-based health insurance among informal workers in urban Bangladesh. PLoS ONE, 11(2), 1-16. https://doi.org/10.1371/journal.pone.0148211

Babatunde, O., \& Akande, T. (2012). Willingness to Pay for Community Health Insurance and its Determinants among Household Heads in Rural Communities in North-Central Nigeria. Irssh. Com, 2(2), 133-142. Retrieved from http://irssh.com/yahoo_site_admin/assets/docs/15_IRSSH-168-V2N2.9005955.pdf

Bärnighausen, T., Liu, Y., Zhang, X., \& Sauerborn, R. (2007). Willingness to pay for social health insurance among informal sector workers in Wuhan, China: A contingent valuation study. BMC Health Services Research, 7, 1-16. https://doi.org/10.1186/1472-6963-7-114

Bawa, S. K., \& Ruchita. (2011). Awareness and Willingness to Pay for Health Insurance: An Empirical Study with Reference to Punjab India. International Journal of Humanities and Social Science, 1(7), 100-108.

Central Bureau of Statistics. (2011). Nepal Living Standards Survey 2010/11: Statistical Report vol I. Kathmandu.

Central Bureau of Statistics. (2014). Statistical Pocket Book of Nepal. Kathmandu.

Department of Health Services. (2018). Annual Report FY 2073/74 (2016/17). Kathmandu. Retrieved from http://dohs.gov.np/wp-content/uploads/2018/04/Annual_Report_2073-74.pdf

Ghosh, M. (2013). Awareness and Willingness to Pay for Health Insurance: A Study of Darjeeling District. IOSR Journal of Humanities and Social Science (IOSR-JHSS), 12(1), 41-47. Retrieved from http://www.iosrjournals.org/iosr-jhss/pages/v12i1.html

Health Insurance Board. (n.d.). Social Health Security Programme: Annual Report FY 2073/74 (2016/17). Kathmandu. Retrieved from http://shs.gov.np

Health Research and Social Development Forum [HERD]. (2016). Keeping under the Umbrella: Universal Health Coverage. Kathmandu.

KOICA-Nepal Health Insurance Support Project [NHISP]. (2014). Comprehensive district assessment for health insurance in Kailali district. Lalitpur, Kathmandu.

Kothari, C. R. (2006). Research methodology: Methods and techniques (2nd ed.). New Delhi: New Age International (P) Limited.

Lang, H. C., \& Lai, M. S. (2008). Willingness to pay to sustain and expand National Health Insurance services in Taiwan. BMC Health Services Research, 8, 1-10. https://doi.org/10.1186/1472-6963-8-261

Lofgren, C., Thanh, N. X., Chuc, N. T. K., Emmelin, A., \& Lindholm, L. (2008). People's willingness to pay for health insurance in rural Vietnam. Cost Effectiveness and Resource Allocation, 6, 1-16. https://doi.org/10.1186/1478-7547-6-16

Ministry of Finance. (n.d.). Economic survey fiscal year 2016/17. Kathmandu. Retrieved from http://mof.gov.np/uploads/document/file/English Economic Survey 2016-17_20180715082204.pdf

Mishra, S. R., Khanal, P., Karki, D. K., Kallestrup, P., \& Enemark, U. (2015). National health insurance policy in Nepal: Challenges for implementation. Global Health Action, 8(1), 8-10. https://doi.org/10.3402/gha.v8.28763

Nepal Law Commission. (n.d.). Constitution of Nepal 2015. Retrieved from http://www.lawcommission.gov.np/en/documents/2016/01/constitution-of-nepal-2.pdf

Nguyen, L. H., \& Hoang, A. T. D. (2017). Willingness to Pay for Social Health Insurance in Central Vietnam. Frontiers in Public Health, 5(April), 1-7. https://doi.org/10.3389/fpubh.2017.00089

Nosratnejad, S., Rashidian, A., \& Dror, D. M. (2016). Systematic review of willingness to pay for health insurance in low and middle income countries. PLoS ONE, 11(6), 1-14. https://doi.org/10.1371/journal.pone.0157470

Prasai, D. (2013). Review of studies on Nepal's national free health care programme. Kathmandu: Nepal Health Sector Support Programme.

Ramadhan, A. A., Rahmadi, A. R., \& Djuhaeni, H. (2015). Ability and Willingness to Pay Premium in the Framework of National Health Insurance System. Althea Medical Journal, 502-505. https://doi.org/10.15850/amj.v2n4.635

Shafie, A. A., \& Hassali, M. A. (2013). Willingness to pay for voluntary community-based health insurance: Findings from an exploratory study in the state of Penang. Malaysia. Social Science and Medicine, 96, 272-276. https://doi.org/10.1016/j.socscimed.2013.02.045 
Shimamura, Y., Matsushima, M., Yamada, H., \& Nguyen, M. T. (2018). Willingness-to-Pay for Family-Based Health Insurance: Findings from Household and Health Facility Surveys in Central Vietnam. Global Journal of Health Science, 10(7), 24. https://doi.org/10.5539/gjhs.v10n7p24

Stoyanov, S. (2017). An analysis of Abraham Maslow's a theory of human motivation. London: Macat International Ltd.

Thi Thuy Nga, N., FitzGerald, G., \& Dunne, M. P. (2018). Family-Based Social Health Insurance for Informal Workers in Vietnam: Willingness to Pay and Its Determinants. Asia Pacific Journal of Public Health, 101053951879978. https://doi.org/10.1177/1010539518799785

World Health Organization. (2010). The World Health Report: Health system financing: The path to universal coverage. World Health Organization. Retrieved from http://apps.who.int/iris/bitstream/handle/10665/44371/9789241564021_eng.pdf;jsessionid=33D299C75FF5 E357896D228702689EAC?sequence $=1$

\section{Copyrights}

Copyright for this article is retained by the author(s), with first publication rights granted to the journal.

This is an open-access article distributed under the terms and conditions of the Creative Commons Attribution license (http://creativecommons.org/licenses/by/4.0/). 